\section{Connecting the mouth and body in 21st century healthcare}

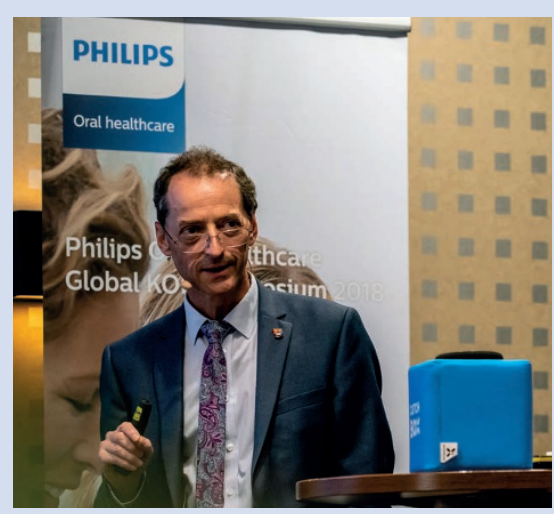

Philips Oral Healthcare hosted its Scientific Symposium (18-19 June): Connecting the Mouth and Body in the 21st Century Healthcare (preceding their attendance at EuroPerio 9) which examined the mounting scientific evidence linking oral and systemic health.

Across two days of lectures and workshops, speakers discussed the newest developments in scientific research, including the significant shift in the perspective on oral health and overall wellbeing, and the changing role of digital technologies in oral care; particularly in the areas of diabetes, cardiovascular disease and pregnancy.

Keynote speaker, Professor Dr R. Bruce Donoff, Dean of Harvard School of Dental Medicine, shared his experience of the integration within the specialties of oral and maxillofacial surgery and oral cancer care, with his address 'Integrate oral health into medicine: past and future state. Dr Niklaus P. Lang, Professor Emeritus at the University of Berne, offered an insight into 'Guided Biofilm Therapy (GBT)', while new health insights emerged from Dr Alvaro Marco del Castillo, around the role of periodontal disease and inflammation in CVD.

Dr Bruno G. Loos, Professor at the Academic Center for Dentistry Amsterdam, demonstrated the need for close working relationships between the medical community and dental hospitals while Professor Dr Purnima Kumar DDS, a leading researcher on the human microbiome, shared findings on glycemic control and oral health. Dental hygienist Elmira Boloori addressed the association of periodontitis and adverse pregnancy outcomes.

Facilitating the discussion throughout the day, Professor Iain Chapple set the scene looking at periodontitis and mortality using chronic kidney disease as a model systemic co-morbidity to address the question of whether periodontitis is causally linked to systemic diseases or whether the association is purely coincidental.

For more information about Philips Oral Healthcare visit https://www.usa.philips. com/c-m-pe/dental-professionals

\title{
Think supplier, think member
}

The British Dental Industry Association (BDIA) has launched a new initiative, 'Think Supplier, Think BDIA Member' to remind the dental profession of the benefits of purchasing from BDIA member companies.

Since 1923 BDIA members have been working closely with the dental profession to provide the quality, innovative and dependable equipment and services that are needed, day in day out. Bound by a comprehensive Professional Code of Practice, bespoke training and a common vision to provide the profession with the best possible service, the Association is urging all those involved in purchasing dental equipment to 'Think Supplier, Think BDIA Member'.

BDIA President, Sonia Tracey of W \& H (UK) urges the dental profession, 'When it comes to purchasing products, remember that BDIA members have committed to their industry Code of Practice requiring the supply of high quality products and services, supported by adequate stocks, spares, maintenance and technical information for the expected life of the product, so when you think supplier, think BDIA member'

Edmund Proffitt, BDIA Chief Executive adds, 'Building on the awareness of our award-winning campaign against counterfeit dental products, we are urging the profession to think about the benefits of purchasing from those suppliers who have signed up to the industry association with its comprehensive Code of Practice and the reassurances that commitment provides to customers'.

\section{Teeth Team trustee awarded MBE}

Ingrid Perry, Secretary and Trustee of the award-winning children's dental health charity Teeth Team, is to be awarded an MBE for 'Services to Education and Improvement of Dental Health in Young People' in the Queen's Birthday Honours List.

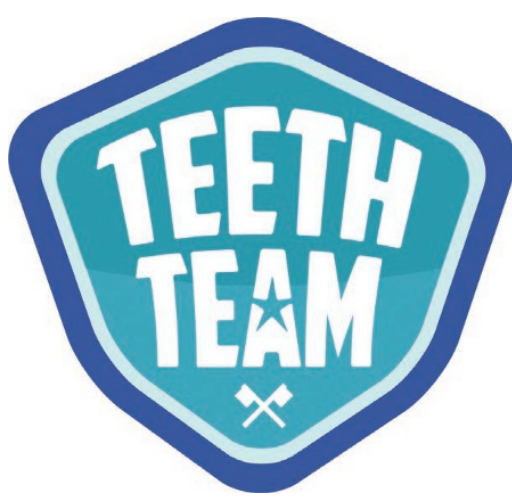

Working closely with local schools for many years, Ingrid was instrumental in helping found the nationally recognised Teeth Team programme, which won 'Best Child Dental Health Initiative' in the DH\&T Awards in 2014. Teeth Team Chair, Chris Groombridge, offered his congratulations: 'We are all delighted to hear that Ingrid will be awarded an MBE. I have worked with Ingrid for many years and this is rightful recognition of her dedication to children's dental health over the entire course of her career.'

Ingrid has over 35 years' experience within the dental profession and has gained national recognition, winning the Patron's Prize for Innovation in 2012 from the NOHPG (National Oral Health Promotion Group). She was also runner-up in the Hull Women in Business, Women of Achievement Awards in both 2012 and 2014 and a finalist in the 2013 Dental Awards in the category of Oral Health Promoter of the Year.

Ingrid will be presented with the Award in the autumn.

For further information about Teeth Team please visit teethteam.org.uk. 